\title{
Anthropogenic influences on the distribution of a Vulnerable coniferous forest specialist: habitat selection by the Siberian musk deer Moschus moschiferus
}

\author{
Jonathan C. Shaght, Brian Milakoviky, Dariya A. Maksimova \\ IVAn V. Seryodin, Vitaliy A. Zaitsev \\ Alexander M. Panichev and Dale G. Miquelle
}

\begin{abstract}
The Siberian musk deer Moschus moschiferus, categorized as Vulnerable on the IUCN Red List, is a small ungulate associated with coniferous forests of East Asia. In Russia the species is hunted both legally and illegally for the commercially valuable musk gland in males. Steep population declines recorded in recent decades have been generally attributed to intensive illegal hunting, but the decline has coincided with increased logging activity and the concomitant expansion of logging roads. We conducted an occupancy analysis in Primorskii Krai, Russia, to elucidate the relative importance of environmental, ecological and anthropogenic features associated with the presence of musk deer. The top model contained covariates related to the abundance of bearded lichen Usnea spp., the distance to a main road and the distance to logging sites, suggesting that both intensive hunting of musk deer (associated with greater accessibility via roads) and logging of habitat are influencing the occurrence of this species. We propose several management actions to limit the negative influence of logging and logging roads on musk deer in Russia, including encouraging logging companies to set aside high conservation value forests (to retain intact forests) and to close logging roads post-harvest (to reduce access by poachers).
\end{abstract}

Keywords Habitat selection, logging, Moschus moschiferus, occupancy, poaching, roads, Russia, Siberian musk deer

Supplementary material for this article can be found at https://doi.org/10.1017/So030605316001617

Jonathan C. Slaght (Corresponding author) and Dale G. Miquelle* Wildlife Conservation Society, 2300 Southern Boulevard, Bronx, NY 10460, USA E-mail jslaght@wcs.org

Brian Milakovsky WWF, Amur Branch, Vladivostok, Russian Federation

Dariya A. Maksimova, Ivan V. Seryodkin ${ }^{*}$ and Alexander M. Panichev Pacific Geographical Institute, Russian Academy of Sciences Far Eastern Branch, Vladivostok, Russian Federation

Vitaliy A. Zaitsev A.N. Severtsov Institute of Ecology and Evolution, Moscow, Russian Federation

*Also at: Far Eastern Federal University, Vladivostok, Russian Federation

Received 19 April 2016. Revision requested 21 July 2016.

Accepted 22 November 2016. First published online 11 May 2017.

\section{Introduction}

T ogging is an important component of the economy of the southern Russian Far East. If conducted properly, some logging can improve habitat for ungulate species by creating a structurally diverse forest, promoting growth of understorey vegetation and providing forage (Slaght et al., in press). However, the logging roads built to facilitate timber removal in the region also provide access for poachers, who target ungulates, such as Siberian musk deer Moschus moschiferus, sika deer Cervus nippon, roe deer Capreolus pygargus, red deer Cervus elaphus and wild boar Sus scrofa, as well as Asiatic black bears Ursus thibetanus and Amur tigers Panthera tigris altaica (Dunishenko et al., 2014; Slaght \& Surmach, 2016; Slaght et al., in press). Although most ungulates are poached for their meat, musk deer, categorized as Vulnerable on the IUCN Red List (Nyambayar et al., 2015), are usually targeted for the musk glands found in males. Musk is used in eastern traditional medicine and the perfume industry (Ostrowski et al., 2016). Since the $1990 \mathrm{os}$ Moschus spp. numbers in Russia and elsewhere have declined sharply, and the decline is generally attributed to intensive harvesting (both legally and illegally) of the glands (Homes, 2004; Nyambayar et al., 2015; Ostrowski et al., 2016).

Musk deer are found throughout much of the higher elevation forests of East Asia. Unlike most ungulates in the southern Russian Far East, which are found in deciduous or mixed forest, musk deer are closely associated with mature and over-mature coniferous forests (Zaitsev, 1991). The deer prefer such forests because of the abundance of pendulant epiphytic lichens (Usnea, Evernia, Bryoria and Ramalina spp., hereafter forage lichens), which can comprise up to $65 \%$ of the musk deer's winter diet, and because the patchy structure of these forests (with dense patches of undergrowth and abundant felled trees) provides excellent cover for these secretive ungulates (Zaitsev, 1991, 2006; Prikhodko, 2003; Domanov, 2013).

The musk deer's coniferous habitat is currently a priority target for logging in the southern Russian Far East. Although the region still contains large expanses of unmanaged, roadless coniferous forests, many of which meet the definition of intact forest landscapes (Aksenov et al., 2003), industrial timber harvesting is continually expanding 
into previously remote areas (e.g. in Ternei County of northern Primorskii Krai (or Province) the cumulative length of forest roads increased an estimated 27 -fold during 19842014, from 228 to 6,278 km; Slaght et al., in press).

The role of logging and its subsequent impact on human access and forest structure is a poorly understood factor influencing musk deer populations. Industrial forest management may affect musk deer populations directly (e.g. through habitat transformation) or indirectly (e.g. through increased hunting pressure as a result of expansion of the logging roads network), or both. Although there is a general consensus that intensive snaring (the most effective means of obtaining musk deer glands) is the primary culprit, Tukhbatulin (2008) argued for the importance of indirect factors, having found that the musk deer population in the Samarga River basin (northern Primorskii Krai) increased significantly in the first year after selective harvesting in spruce-fir forests (probably because of the abundance of accessible forage lichens in the logging slash) but then dropped catastrophically over the next 4 years as hunting and poaching pressure increased. Extensive anecdotal evidence from the region confirms the key importance of access: many hunters, game managers and rangers have stated that musk deer populations plummet in newly roaded forests, irrespective of logging intensity.

However, much literature also points to a significant direct impact of timber harvesting on musk deer; for example, in the late Soviet period (when hunting and poaching of the species for its glands was relatively limited), sharp reductions in musk deer populations were observed after clear-cutting of mature coniferous forests in Chuguyevka County (central Primorskii Krai; Ribachuk, 1982). Similarly, Domanov (2013) observed that musk deer nearly disappeared after logging in relict patches of mature spruce-larch forests in the Tukurungra Mountain range in Amurskaya Province, where commercial hunting of musk deer was almost absent. The loss of cover and sources of forage lichens after logging and forest fires was identified as an important driver of musk deer population declines in both the Sikhote-Alin Mountains of Primorskii Krai and on Sakhalin Island, where the local subspecies of musk deer is listed as Endangered in the Red Book of the Russian Federation (Zaitsev, 2006; Ministry of Natural Resources, 2008). Our objective was to assess the influence of logging activities (including road management) on the relative abundance of musk deer and to develop guidelines for reducing anthropogenic impacts on the species. We believed that musk deer would prefer areas with fewer roads, less logging, and greater availability of lichens.

\section{Study area}

The study was conducted in the central Sikhote-Alin Mountains of Ternei and Krasnoarmeisk Counties,
Primorskii Krai, Russia, in and adjacent to the SikhoteAlin Biosphere Reserve (Fig. 1). The Biosphere Reserve is an IUCN Category Ia federally protected area, where resource extraction (e.g. hunting, logging, collection of nontimber forest products) is strictly prohibited and other human use (e.g. recreation) is largely restricted (although all these activities occur in adjacent lands). The study area is mountainous, at $266-1,385 \mathrm{~m}$ altitude, with forests dominated by Ayan spruce Picea ajanensis, Manchurian fir Abies nephrolepis and Korean pine Pinus koraiensis, and with a significant component of Dahurian larch Larix dahurica and yellow birch Betula costata. Korean spruce Picea koraiensis sometimes replaces Ayan spruce in stream and river valleys. At lower elevations temperate hardwood species begin to appear, including Amur linden Tilia amurensis, small-leaf maple Acer mono, Manchurian ash Fraxinus mandshurica, mountain elm Ulmus laciniata and Mongolian oak Quercus mongolica.

The dominant forest leaseholder in the study area (in the lands outside Sikhote-Alin Biosphere Reserve) is Joint Stock Company TerneyLes (hereafter TerneyLes), which cuts timber primarily using shelterwood harvesting, a management technique that removes enough canopy trees to allow light into the understorey to stimulate regeneration but leaves enough to provide some protective shade (hence the term shelter). This method leaves a high proportion of standing trees post-harvest, including many that will never be harvested, such as the Korean pine, logging of which is banned (CITES, 2017) because of its high ecological and social value as a source of pine nuts. Many large trees are also left standing when, because of the mountainous relief, skid trails veer apart and the space between them is unreachable by harvesters from either side. This increases the level of retention and often leads to unharvested islands of pine and surrounding spruce and fir trees amidst logging sites.

\section{Methods}

\section{Survey design}

We conducted surveys in or near the northern border of Sikhote-Alin Biosphere Reserve, with surveys focused on three sites: Nechet, Taezhnoe and Venera regions (Fig. 1). By including transects both inside (with no logging and few roads) and outside the protected area (with logging and many roads) we were able to capture the variety of conditions available for musk deer in the study area. We placed a network of transects at regular intervals (c. $1 \mathrm{~km}$ apart), starting from access points (roads) within our grid of predetermined management regimes (e.g. protected and selectively harvested sites). Surveyors walked along transects, guided by global positioning systems, and stopped at data points every $250 \mathrm{~m}$ to record habitat parameters, including harvest 


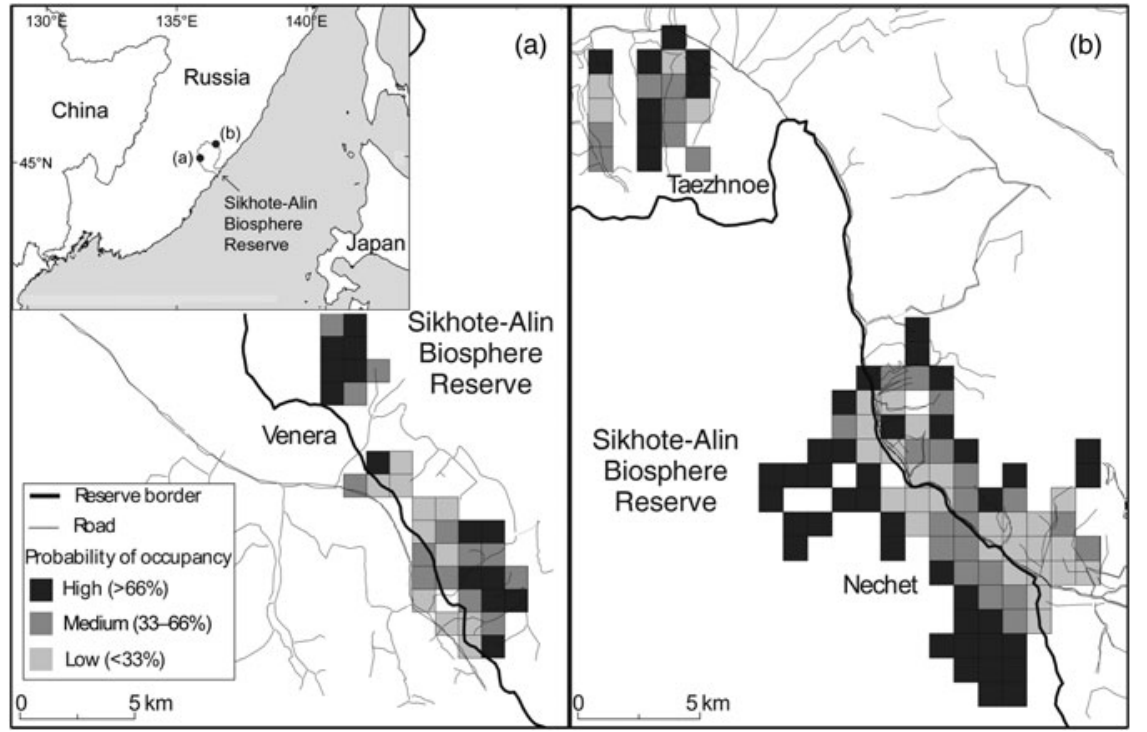

FIG. 1 Probability of musk deer Moschus moschiferus occupancy within the (a) Venera and (b) Taezhnoe-Nechet regions of the study area, in and adjacent to the Sikhote-Alin Biosphere Reserve, Primorskii Krai, Russia. regime, snow depth, tree stand composition, canopy cover, topography, aspect, elevation, distance to roads, distance to harvest sites, and abundance/availability of lichens (Supplementary Table S1). Fresh tracks (i.e. $<24$ hours old) of musk deer, other ungulates, predators or people were recorded whenever they bisected the transect, and the same environmental variables were collected.

Lichen data were assessed in two ways: lichen load and lichen availability. To estimate lichen load, trees in a given plot (determined as being in the plot using a relascope with a basal area factor of 1.0) were assessed visually for musk deer forage lichens as being $0-10,10-50$ or $>50 \%$ lichen covered. Although much of the lichen load is unavailable to musk deer at any given time (being high up on the tree), some portion of it becomes available when branches and attached lichens are brought down by wind. The availability of lichens $\leq 1.2 \mathrm{~m}$ from the ground (the approximate height a musk deer can reach) was estimated on a scale of $0-3$ (low to high availability).

\section{Data analysis}

We used a presence/absence approach (MacKenzie \& Royle, 2005) to elucidate habitat availability vs use for musk deer, and to assess the relative importance of environmental, ecological and anthropogenic features associated with occupancy by musk deer. Occupancy modelling uses maximum likelihood to incorporate detectability of a target species into the estimation of site occupancy (Royle \& Nichols, 2003). Covariates for the occupancy analysis were selected based on an earlier pilot study (Slaght et al., 2012) after removing any correlated covariates (where $r^{2} \geq 0.70$ ). We created a grid of $1 \mathrm{~km}^{2}$ survey units and laid it over the study area.
Any cell that contained four or more data points (or spatial replicates) was included in the analysis. We selected this number of spatial replicates based on recommendations in MacKenzie \& Royle (2005) for the number of data points needed per survey unit for an accurate estimate of the probability of occupancy, by assuming a true occupancy value of 0.5 (i.e. $50 \%$ site occupancy) and a detection probability of 0.4 (i.e. an individual musk deer had a $40 \%$ chance of being detected). These assumptions were conservative given that an adult male has a winter home range of c. $2 \mathrm{~km}^{2}$ (twice the size of our survey unit; Zaitsev, 2006) and we conducted our fieldwork in winter (when musk deer were easily detectable from tracks in snow).

To model occupancy we developed a suite of a priori candidate models (based on results of single parameter tests) to determine which covariates had the greatest impact on musk deer occupancy (Supplementary Table S2), and then estimated the maximum likelihood of each model being the best fit for the data. We used 14 competing models with nine covariates to provide a quantitative assessment of the probability of musk deer occupancy of a given area. Data were analysed following the framework for a single-species, single-season occupancy model in MacKenzie et al. (2006). We determined model fit using Akaike's information criterion (AIC; Burnham \& Anderson, 2002), and identified the best model by the lowest AIC score. However, any models within two AIC units are considered to be equally viable, and any model within seven AIC units is considered to be competitive.

To describe the predictive accuracy of the top model we estimated $r^{2}$ following methods similar to those of Skalski et al. (1993). Specifically, we assessed the total variation in the data by comparing the global and null models, and then evaluated the proportion of that variation explained 
by the top-ranked model. We defined the global model as a model using all of the covariates in the occupancy parameter. We analysed the data in PRESENCE v. 6.1 (Patuxent Wildlife Research Center, Laurel, USA), standardizing covariates using z-scores prior to analysis, and displayed the results using ArcGIS v. 9.3 (ESRI, Redlands, USA).

\section{Results}

During 12 December 2012-8 March 2013 we walked c. $158 \mathrm{~km}$ of transects ( $88 \mathrm{~km}$ in Nechet, $25 \mathrm{~km}$ in Taezhnoe and $45 \mathrm{~km}$ in Venera) and collected habitat parameters from 1,206 points. All surveys were conducted in potential musk deer habitat in coniferous forest (mean forest cover was 73\%), at elevations of $355^{-1,050} \mathrm{~m}($ mean $=613 \mathrm{~m})$, in unlogged areas as well as areas that had experienced logging. We recorded wildlife sign on 694 occasions, including 524 records of musk deer tracks, by far the most common ungulate in the study area.

The results of model selection are in Table 1. The top model suggested that musk deer selected sites with high lichen load ( $\beta=0.88 \pm \mathrm{SE} 0.44$ ), larger distance to main road $(\beta=0.47 \pm \mathrm{SE} 0.30)$ and larger distance to harvest site $(\beta=1.25 \pm$ SE 0.45). There were two other models with $\Delta$ AIC $<2$, and six models in total with $\Delta$ AIC $<7$. After eliminating top models with uninformative parameters (those with confidence intervals that overlapped o), we were left with various iterations of models with the same three covariates.

We found that our top model explained $86 \%$ of the variation in the data $\left(r^{2}=0.86\right)$, suggesting very strong fit. However, we note that the global model used to estimate $r^{2}$ was not a saturated model (i.e. one with occupancy beta coefficients for each site), and thus our $r^{2}$ value is probably an overly optimistic assessment of the top model's explanatory power.

\section{Discussion}

Our analysis suggests that both environmental and anthropogenic parameters were important in delineating musk deer occurrence. Musk deer preferred areas with high lichen loads that were further from the main road and further from areas that had been logged. The inclusion of distance to main road as a covariate in four of the top six models provides evidence that direct human harvest (e.g. hunting and poaching) is influencing musk deer distribution. In other words, the more inaccessible an area, the greater the likelihood that musk deer will be present. Clearly, it is easier and more efficient for hunters and poachers to establish snare lines for musk deer that are easily accessible from a road network. Hence, our results provide evidence that human harvest is influencing the distribution of musk deer across the landscape, both inside and outside the protected area.

Similarly our analysis suggests logging has a negative influence on the probability of musk deer occurrence at a site. Distance to harvest site was the only single-covariate model considered to be competitive (models with $\triangle \mathrm{AIC}<7$ ), and all six of the top models contained this covariate, suggesting that it may be an even more important predictor of musk deer occurrence than road access. There appears to be an additive effect of roads and harvest, given that separately the covariate distance to main road scored low $(\triangle \mathrm{AIC}=10.1)$ but when coupled with distance to harvest it appeared in four of the top six models.

It is possible that the negative effect of timber harvesting on musk deer use is, like the effect of distance to roads, connected primarily to access. The logging roads (and even skid trails) that fan through the forest from the main roads facilitate access by off-road vehicles as well as on foot. Setting snares for musk deer around the perimeter of freshly logged sites is a common practice, as the ungulates are attracted to the accessible lichens in the logging slash and may even be drawn to the sound of falling trees (Zaitsev, 2006; Tukhbatulin, 2008).

The importance of lichen loading in all three top models that could be considered equally competitive $(\Delta \mathrm{AIC}<3)$ in predicting use of a site by musk deer suggests that logging is also important as an instrument of habitat transformation. The fact that high lichen load alone was uninformative $(\triangle \mathrm{AIC}=18.5)$ seems to contradict this conclusion but could be explained by the fact that mature coniferous forests with relatively high lichen loads are common in the unmanaged portions of the landscape. In such areas the supply of lichens is likely to exceed the needs of musk deer, and so lichens do not act as a limiting resource, but in managed forests, where the supply of large, old trees with open crowns (the best substrate for pendulant lichens) is greatly reduced, lichen load in combination with reduced human access drives musk deer occurrence. However, exactly how harvest is influencing lichen distribution and abundance remains unclear.

Further research is necessary to clarify the influence of timber harvesting on lichen loads and musk deer occupancy. The type and intensity of logging vary across the landscape, from low-impact selection of individual, large spruce trees to commercial clearcuts. We observed some partially harvested logging sites where the lichen load remained relatively high, and in some cases extremely long 'beards' of pendulant lichens were most common on the sides of old trees that faced open logging trails. Harvest experiments in Finland have suggested the possibility that selection harvests may actually improve conditions for pendulant lichen growth (Storaunet et al., 2008, 2014), where 400-600 mature spruce trees with Usnea longissima per ha were retained post-harvest, and the volume of the 
TABLE 1 Models of musk deer Moschus moschiferus occupancy in and adjacent to the Sikhote-Alin Biosphere Reserve, Primorskii Krai, Russia (Fig. 1), with $\triangle$ AIC (the difference between the model with the lowest AIC value and the top model), Akaike weight (the probability that a model is the best fit of all candidate models), $\lambda$ (the likelihood that a given model is the top model), and $K$ (the number of parameters used in each model). Competitive models (i.e. those within $7 \Delta \mathrm{AIC}$ units of the top model) are shaded grey.

\begin{tabular}{|c|c|c|c|c|}
\hline Model & $\triangle \mathrm{AIC}$ & Akaike weight & $\lambda$ & K \\
\hline Distance to harvest site + distance to main road + high lichen load & 0.0 & 0.43 & 1.00 & 5 \\
\hline Distance to harvest site + distance to main road + high lichen load $+\%$ dark conifers & 0.9 & 0.28 & 0.64 & 6 \\
\hline High lichen load + distance to harvest site & 1.9 & 0.17 & 0.38 & 4 \\
\hline Distance to harvest site + distance to main road & 3.6 & 0.07 & 0.17 & 4 \\
\hline Distance to harvest site + distance to main road + lichen availability & 5.5 & 0.03 & 0.06 & 5 \\
\hline Distance to harvest site & 6.8 & 0.01 & 0.03 & 3 \\
\hline High lichen load + distance to main road & 9.6 & 0.00 & 0.01 & 4 \\
\hline Distance to main road & 10.1 & 0.00 & 0.01 & 3 \\
\hline Distance to harvest site + distance to main road & 11.0 & 0.00 & 0.00 & 4 \\
\hline$\%$ Dark conifers & 18.0 & 0.00 & 0.00 & 3 \\
\hline$\%$ Dark conifers + high lichen load & 18.1 & 0.00 & 0.00 & 4 \\
\hline High lichen load & 18.5 & 0.00 & 0.00 & 3 \\
\hline Forest harvested or not & 20.5 & 0.00 & 0.00 & 3 \\
\hline Topographic position index + elevation + aspect $+\%$ dark conifers + high lichen load & 22.3 & 0.00 & 0.00 & 7 \\
\hline
\end{tabular}

lichen increased (probably as a result of heightened light and moisture levels compared to the dense canopy of the unlogged control).

\section{Management recommendations}

A simple comparison of logged vs unlogged forests does not tell the full story of how timber harvest is affecting musk deer. Our data appear to show there are at least three factors driving musk deer distribution in a selectively harvested landscape: distance from roads, distance from harvest sites, and amount of lichen. In Canada, a strategy has been developed for conservation of the caribou Rangifer tarandus, another Vulnerable ungulate associated with lichens and old-growth forests, which includes both exclusion of habitats from logging and the use of practices on logging sites that maintain lichen-rich trees (Armleder \& Stevenson, 1996; Miège et al., 2001). Musk deer clearly respond to high lichen loads and, given our observations that forage lichens thrive in some partially harvested stands in the study area, it is possible that similar guidelines could be developed in Russia. However, our results did not identify an interpretable mechanism by which logging influences high lichen loads (besides the crude and obvious observation that high intensity harvests such as clearcutting reduce lichen loads to near zero). In the absence of clear, negative impacts of harvest on lichen abundance it is difficult to make specific management recommendations to reduce lichen loss and improve habitat for musk deer without further research on the role of timber harvest on lichen load.

We were unable to tease apart the direct (habitat transformation) and indirect (increased human access) impacts of timber harvesting on musk deer populations, based on our results. We believe that both of these factors contribute to reducing the quality of managed spruce-fir forests with roads in comparison to inaccessible, intact forests. As such, a strategy for conserving populations of this Vulnerable, commercially valuable species should include protection of prime habitats from both road building and timber harvesting and, where harvesting occurs, eliminating access along forest roads after harvesting is discontinued. Protected patches should be large enough to support a musk deer social unit (700-1,00o ha; Zaitsev, 2006), although for long-term conservation of genetic diversity larger habitat blocks $(25,000-45,000 \mathrm{ha})$ may be necessary (Zaitsev et al., 2013).

The protected area network in the central Sikhote-Alin Mountains is already well developed, and the prospect of establishing a large number of additional protected areas is unlikely. Consequently, other mechanisms for securing habitat should be considered. One possibility would be to set aside high conservation value forests from logging, in the framework of Forest Stewardship Council voluntary forest certification; for example, TerneyLes has agreed to set aside several massifs of intact Korean pine-spruce-fir forests to the north of Sikhote-Alin Biosphere Reserve. This practice should be extended to forests leased by other logging companies in the region and, where possible, adjacent massifs should be set aside to increase the effective size of high conservation value forest massifs. The conservation of intact, mature and overmature coniferous forests would benefit the conservation of other key game species, such as the sable Martes zibellina and Eurasian lynx Lynx lynx, as well as rare species such as the Near Threatened Siberian spruce grouse Falcipennis falcipennis.

Roads could be closed post-harvest by removing bridges or using barricades such as earthen berms at key access 
points to reduce or eliminate vehicular access (Slaght \& Surmach, 2016). Such actions have had significant impacts in protecting wildlife species and restoring habitat elsewhere (Forman et al., 2003; Switalski \& Nelson, 2011; Kleinschroth et al., 2015). Road closures have already been undertaken on a limited scale by TerneyLes to reduce human access to ecologically sensitive riparian zones, and could be extended to coniferous forests as well. If human access could be restricted via road management, it is not only musk deer populations that would benefit: in the southern Russian Far East, roadless areas are typically bypassed by people seeking areas that are accessible by vehicle, and thus closures are a simple and inexpensive means to convert a forest from high to low human use (Slaght \& Surmach, 2016). Road closures are likely to reduce poaching pressures on a wide variety of species, including ungulates, tigers, bears and salmon Oncorhynchus sp., and benefit logging leaseholders by reducing the risk of anthropogenic fire and illegal timber extraction (Slaght et al., in press). As such, closures facilitate resource extraction in a way that meets the needs of the local economy and global timber demand, and also minimizes the negative impact of this activity on natural communities.

\section{Acknowledgements}

We thank field assistants and volunteers G. Bannikov, A. Gabrielson, E. Tabalykin, M. Pozdeev, E. Petrunenko, M. Borisov, A. Kosolapova and D. Maksimov. F. Maisels and T. Rayden assisted with a literature review. D. Tempel provided advice and support regarding occupancy modelling. This project was made possible by grants awarded by the WWF-IKEA Partnership and the Wildlife Conservation Society Research Fellowship Program (for DAM).

\section{Author contributions}

JCS provided primary study design, primary statistical analysis, and played a lead role in article preparation. BM and DGM contributed significantly to editing the article, secured funding for the project, collected field data, and played an advisory role in study design and data analysis. DAM, IVS, VAZ and AMP provided primary data collection, secured permits to work in the protected area, and played a secondary role in editing.

\section{References}

Aksenov, D.E., Dobrynin, D.V. \& Dubinin, M.Y. (2003) Atlas of Intact Forest Landscapes of Russia. World Resources Institute Press, Washington, D.C., USA.
Armleder, H.M. \& Stevenson, S.K. (1996) Using alternative silvicultural systems to integrate mountain caribou and timber management in British Columbia. Rangifer, Special Issue No. 9, 141-148.

Burnham, K.P. \& Anderson, D.R. (2002) Model Selection and Multimodel Inference. Springer, New York, USA.

CITES (2017) The CITES Appendices. Http://www.cites.org/eng/app/ index.shtml [accessed 6 February 2017].

Domanov, T.A. (2013) Ecology of musk deer (Moschus moschiferus, Linnaeus 1758) on the Tukurungra Range. PhD thesis. Irkutskaya Agricultural Academy, Irkutsk, Russia. [In Russian]

Dunishenko, Y.M., Ermolin, A.B., Darensky, A.A., Dolinin, V.V., Solovey, A.A., Golub, A.M. \& Zhukov, A.Y. (2014) Hunting Resources of Khabarovsky Krai. Khabarovsk Provincial Typography, Khabarovsk, Russia.

Forman, R.T.T., Sperling, D., Bissonette, J.A., Clevenger, A.P., Cutshall, C.D., D Ale, V.H. et al. (2003) Road Ecology: Science and Solutions. Island Press, Washington, D.C., USA.

Homes, V. (ed.) (2004) No License to Kill: The Population and Harvest of Musk Deer and Trade in Musk in the Russian Federation and Mongolia. TRAFFIC Europe, Cambridge, UK.

Kleinschroth, F., Gourlet-Fleury, S., Sist, P., Mortier, F. \& Healey, J.R. (2015) Legacy of logging roads in the Congo Basin: how persistent are the scars in forest cover? Ecosphere, 6, 1-17.

MacKenzie, D.I. \& Royle, J.A. (2005) Designing occupancy studies: general advice and allocating survey effort. Journal of Applied Ecology, 42, 1105-1114.

MacKenzie, D.I., Nichols, J.D., Royle, J.A., Pollock, K.H., BAiley, L.L. \& Hines, J.E. (2006) Occupancy Estimation and Modeling. Academic Press, New York, USA.

Miège, D.J., Armleder, H.M., Waterhouse, M.J. \& Goward, T. (2001) A Pilot Study of Silvicultural Systems for Northern Caribou Winter Range: Lichen Response. Working Paper 56/2001. Research Branch, British Columbia Ministry of Forests, Victoria, Canada.

Ministry of Natural Resources of the Russian Federation (2008) Strategy for conservation of the Sakhalin musk deer in Russia. Official order №9-R, 24 March 2008. Moscow, Russia. [In Russian]

Nyambayar, B., Mix, H. \& Tsytsulina, K. (2015) Moschus moschiferus. The IUCN Red List of Threatened Species 2015: $e$. T13897A61977573. Http://dx.doi.org/10.2305/IUCN.UK.2015-2.RLTS. T13897A61977573.en.

Ostrowski, S., Rahmani, H., Ali, J.M., Ali, R. \& Zahler, P. (2016) Musk deer Moschus cupreus persist in the eastern forests of Afghanistan. Oryx, 50, 323-328.

Prikhod ko, V.I. (2003) Musk Deer: Origin, Systematics, Ecology, Behaviour and Communication. GEOS Books, Moscow, Russia. [In Russian]

Ribachuк, V.N. (1982) Influence of Logging on Winter Feed of the Musk Deer. Moscow University Herald (Vestnik Mosckovskovo Universiteta). Geografiya, Moscow, Russia. [In Russian]

Royle, J.A. \& Nichols, J.D. (2003) Estimating abundance from repeated presence-absence data or point counts. Ecology, 84, 777-790.

Skalski, J.R., Hoffman, A. \& Smith, S.G. (1993) Testing the significance of individual- and cohort-level covariates in animal survival studies. In Marked Individuals in the Study of Bird Populations (eds J.-D. Lebreton \& P.M. North), pp. 9-18. Birkhauser Verlag, Basel, Switzerland.

Slaght, J.C., Maksimova, D.A., Miquelle, D.G., Seryodkin, I.V., Milakovsky, B., Zaytsev, V.A. \& Pimenova, E.A. (2012) The influence of logging on musk deer resource selection: preliminary results from the central Sikhote-Alin. In Innovative Technologies in 
Veterinary Medicine, Animal Husbandry, and Nature Conservation in the Russian Far East. Conference Proceedings, 1-2 November 2012 (ed. L.V. Zhilyakov), pp. 183-189. Primorskaya State Academy of Agriculture, Ussuriisk, Russia. [In Russian]

Slaght, J.C., Miquelle, D.G. \& Tukhbatulin, G.A. (in press) Logging roads and Amur tigers in Russia: demonstrating the threat and proposing solutions. Proceedings of the International Conference on the Amur Tiger: Population Status, Problems, and Conservation Prospects. 13-15 December 2015. Institute of Biology and Soil Science, Vladivostok, Russia. [In Russian]

SlaGHT, J.C. \& SurmaCh, S.G. (2016) Blakiston's fish owls Bubo blakistoni and logging: applying resource selection information to endangered species conservation in Russia. Bird Conservation International, 26, 214-224.

Storaunet, K.O., Rolstad, J. \& Rolstad, E. (2014) Effects of logging on the threatened epiphytic lichen Usnea longissima: an experimental approach. Silva Fennica, 48, 1-13.

Storaunet, K.O., Rolstad, J., Toeneiet, M. \& Rolstad, E. (2008) Effect of logging on the threatened epiphytic lichen Usnea longissima: a comparative and retrospective approach. Silva Fennica, 42, 685-703.

Switalski, T.A. \& Nelson, C.R. (2011) Efficacy of road removal for restoring wildlife habitat: black bear in the Northern Rocky Mountains, USA. Biological Conservation, 144, 2666-2673.

Tuknвatulin, G.A. (2008) Influence of Timber Harvesting and Hunting on Musk Deer Population Density. Unpublished report. Biological Soil Institute, Far Eastern Branch of Russian Academy of Sciences, Vladivostok, Russia. [In Russian]

Zaitsev, V.A. (1991) Musk Deer of the Sikhote-Alin. Ecology and Behavior. Nauka, Moscow, Russia. [In Russian]
Zaitsev, V.A. (2006) Musk Deer: Ecology, Population Dynamics, Perspective for Conservation. Biodiversity Conservation Center Press, Moscow, Russia.

Zaitsev, V.A., Seryodkin, I.V., Pimenova, E.A. \& Maksimova, D. A. (2013) Necessary measures for the conservation of the musk deer (Moschus moschiferus), their theoretical basis and the condition of the protected areas network in Primorsky Province. In Proceedings of the Far-Eastern Conference on Nature Conservation Problems, 2527 September 2013. BSPU-Press, Blagoveshchensk, Russia.

\section{Biographical sketches}

JONATHAN SLAGHT is interested in wildlife distributions (primarily birds) in the Russian Far East, and in identifying the resources and conservation issues that influence those distributions. BRIAN MILAKOVSKY works on developing practical methods for maintaining populations of rare and threatened species during industrial forest management in the Russian Federation. DARIYA MAKsimova uses radio tracking, camera traps and direct observation to study musk deer ecology at the Sikhote-Alin Biosphere Reserve in Russia. Ivan SERYODKIN is a specialist on large predators and ungulates, with a focus on their conservation in the Russian Far East. Vitaliy ZAITSEV studies the ecology, behaviour and population dynamics of ungulates and predators, the structure of bird and mammal communities, and wildlife management and research methodologies. Alexander Panichev studies ungulate ecology, with a focus on explaining the causes of their geographical distribution. DALE Miquelle coordinates the Wildlife Conservation Society's conservation efforts in Russia, with a focus on developing strategies to conserve and restore Amur tiger habitat. 